\title{
ESP BLOCK FOR ONCOLOGIC BREAST SURGERY: CAN IT BE USED AS A REGIONAL ANESTHESIA TECHNIQUE?
}

Juan Carlos Sosa Nicora, ' Adriana Inés Acosta,' Eduardo Alló .

'. Centro Medico de Mastologia. Asuncion, Paraguay.

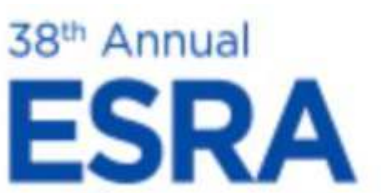

Congress
BILBAO, SPAIN

2019

\section{Background and Aims:}

The mechanisms of the Erector Spinae Block are still poorly understood. 'Since the ESP was first described by Mauricio Forero in $2016^{2}$ only a couple of case reports ${ }^{3,4}$ are available that describe the use of ESP without general anesthesia. 5,6

Our aim is to use the ESP technique with a continous catheter

(E-Cath ${ }^{\circledR}$ - Pajunk, 20I8) ${ }^{7}$ as a regional technique in oncologic breast surgery with the patient on spontaneous ventilation without the use of orotracheal intubation or a supraglotic device.

\section{Methods:}

Retrospective analisis

April 2018 -April 2019

$n=13$

Same Surgical Team every time

Surgeries Carried Out:

$>$ Quadrantectomy with Axillar Lymph Node Removal $(n=3)$

$>$ Quadrantectomy w/o Axillar Lymph Node Removal $(n=3)$

$>$ Modified Radical Mastectomy with Axillar Lymph Node Removal $(n=3)$

$>$ Central Quadrantectomy $(n=2)$

$>$ Multiple Node Biopsy $(\mathrm{n}=\mathrm{I})$

Lactiferous ducts Removal $(n=l)$

Primary End Point: Need to convert to General Anesthesia

Before skin incision: Sedation with IV Midazolam 2 mgr and IV Propofol 20-30 mgr.

Surgeon Undertook intermitent tegumentary testing incision.

Need of use of LA by surgeon ws noted.

Discharge to ward with IV Methamizole and IV Ketorolac.

\section{ESP Technique:}

Pre-Medication: Fentanyl Iug/kg and Midazolam $0,03 \mathrm{ug} / \mathrm{kg}$

Sitting Position.

Ultrasound-Guided location of Transverse Process of T5

In Plane placement of E-Cath $18 \mathrm{G} \times 75 \mathrm{~mm}$ Needle and Catheter First Shot: Lidocaine 2\% $20 \mathrm{cc}$

Latency: Between 10 and 30 mins (mean 23 mins)

Allow latency time with awake patient and monitor sign of LA toxicity.
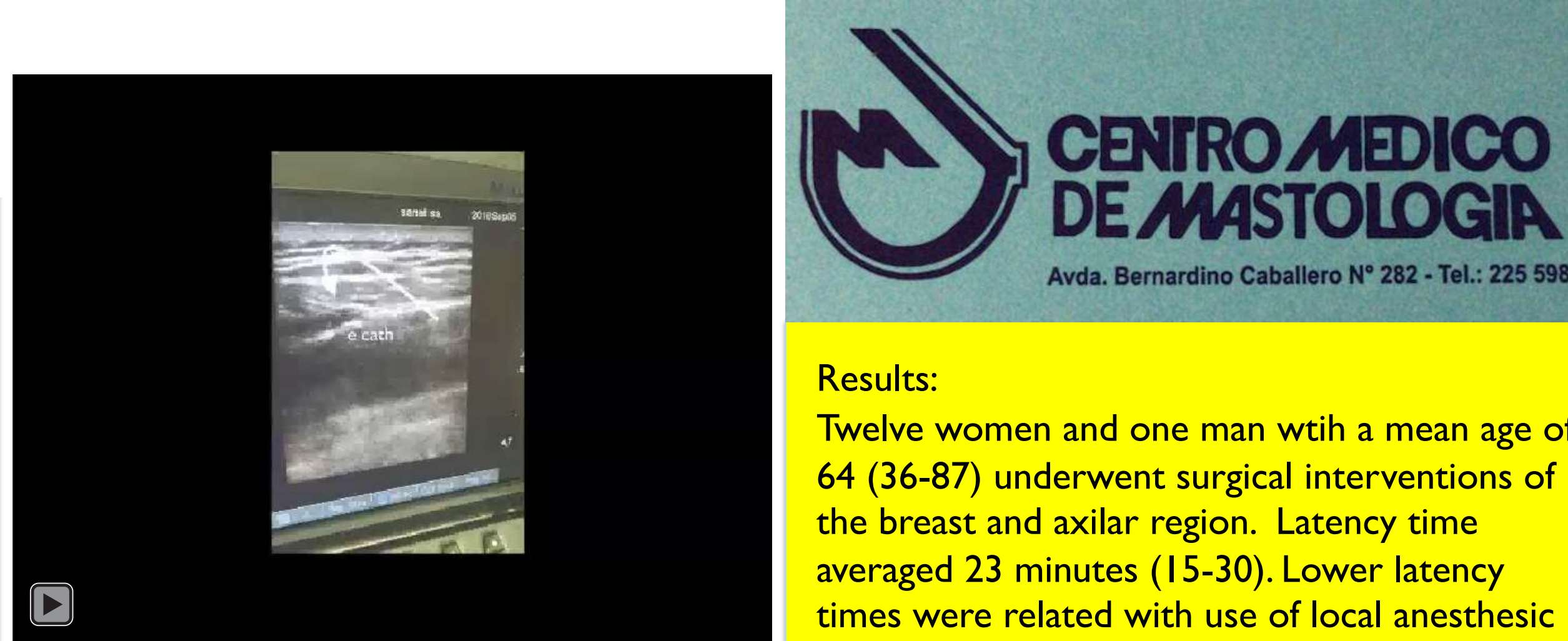

Results:

Twelve women and one man wtih a mean age of 64 (36-87) underwent surgical interventions of the breast and axilar region. Latency time averaged 23 minutes (15-30). Lower latency times were related with use of local anesthesic by the surgeon ( 4 cases in superficial skin plane). Average intervention time was 70 minutes (45120) and additional bolus of intraoperative lidocaine was administered in 7 patients.

No patient required conversion to general anesthesia nor rescue analgesia in the post operative period. The last patient in the series was a high risk patient (severe valvulopathy, high ELVDP and CKD ) so she recieved analgesia through an elastomeric pump and NSAIDs were spared. All patients were discharged after 24 hours without complications.

References:

I.- Erector spinae plane block: an innovation or a delusion?

Korean J Anesthesiol. 2019;72(I):I-3. Published online January 3I, 2019

Conclusions:

2.- Forero M,Adhikary SD, Lopez H,Tsul C, Chin KJ. The erector spinae plane block: A novel analgesic technique in thoracic neuropathic pain. Reg Anaesth ESP block can be used as regional Pain Med.2016;41:62I-7 anesthesia technique for oncologic 3.- Kwon WJ, Bang SU, Sun WY. Erector spinae plane breast surgery using a continuos catheter.

block for effective analgesia after total mastectomy with sentinel or axillary lymph node dissection: a report of three cases.J Korean Med Sci 2018; 33: e29l.

4.- Altıparmak B, et al. Ultrasound guided erector spinae plane block for postoperative analgesia after augmentation mammoplasty: case series. Rev Bras

This technique can provide good post operative analgesia and can be Anestesiol. 2019. used as the sole strategy for post operative analgesia .

Further studies are needed to evaluate overall safety for this procedure since high doses of Local Anesthesics are required. https://doi.org// 0.1016/j.bjane.2018.12.008

5.-Kimachi PP, Martins EG, Peng P, Forero M.The erector spinae plane block provides complete surgical anesthesia in breast surgery: a case report. A A Pract. 2018; I I:186-8.

6.- De Cassai A, Marchet A, Ori C.The combination of erector spinae plane block and pectoralis blocks could avoid general anesthesia for radical mastectomy in high risk patients. Minerva Anestesiol. 2018; 84:I420-I42I

7.- Ip V.H.Y. et al.The catheter-over-needle assembly offers greater stability and less leakage compared to the traditional counterpart in continuous interscalene nerve blocks: a randomized, patient-blinded study, Can.J.Anesth. 2013; 60: 1272-1273 